\title{
Dynamic differences in child bilinguals' production of diphthongs
}

Vincent Chanethom

Department of Linguistics, New York University, USA

https://doi.org/10.36505/ExLing-2011/04/0013/000182

\begin{abstract}
This paper examines the cross-linguistic phonetic interactions in the production of diphthongs by French-English bilingual children. The study aims to investigate (1) whether English diphthongs (e.g. /aI/ as in bye) and French tautosyllabic vowel-glide combinations (e.g. /aj/ as in baille 'yawn') have different phonetic implementations, and if so, (2) whether bilingual children maintain two separate categories. Using SSANOVA to compare formant contours, the results showed distinct phonetic patterns for each category. The results also indicated that bilingual children with a reduced amount of input in French show overlapping acoustic properties.
\end{abstract}

Key words: Bilingualism, diphthongs, SSANOVA, language acquisition.

\section{Introduction}

This study examines the phonetic interaction between the languages of French-English bilingual children with respect to diphthong production. Previous studies (e.g. Flege 2002) indicated that early bilinguals show smaller degrees of L1-L2 interference than late bilinguals. The majority of these studies, however, investigated the phonetic properties of child bilingual speech using what Tsukada et al. (2005) called a "retrospective developmental design" (p.266), in which adult bilinguals with different ages of first exposure to L2 were compared. Furthermore, a large number of these studies centered mainly on the acquisition of monophthongs. Few studies have examined whether complex segments, such as diphthongs, follow the same pattern of acquisition. For instance, tautosyllabic vowel-glide (VG) combinations in English (e.g. bye) and in French (e.g. baille 'yawn') have different phonological stati. This VG combination corresponds to a single segment (i.e. a diphthong) in English, but two separate segments (i.e. vowel+glide) in French. This paper presents a picture-naming experiment with (1) adult monolingual speakers to examine whether these two categories also have different phonetic implementations, and (2) 6-7 year old bilingual children to investigate whether or not they maintain two separate categories.

To compare these two categories, the current study uses a relatively novel methodology, the Smoothing Spline ANOVA (Davidson 2006). This is a better statistical tool for analyzing diphthongs than previously used techniques. With this technique, it is not only possible to determine whether there are significant acoustic differences in formant structure, but also where these differences lie. Harrington and Cassidy (1994) argue that

ExLing 2011: Proceedings of 4th Tutorial and Research Workshop on Experimental Linguistics, 25-27 May, Paris, France 
the best way to represent diphthongs is by capturing their dynamicity, hence the need of multiple reference points for their analysis. For instance, Tsukada (2008) took three measurements, at the $20^{\text {th }}, 50^{\text {th }}$, and $80^{\text {th }}$ percentiles along the formant trajectories. However, three points are not sufficient to fully capture differences between diphthongs.

In this study, 50 equidistant reference points were extracted using a Praat script (Boersma and Weenink 2011). The curves formed by these 50 points were then submitted to statistical comparisons using SSANOVA, which was run in R. In order to locate the region(s) along the curves with significant differences, 95\%-Bayesian confidence intervals were constructed around the main effect smoothing splines (see Figure 1). The parts of the curves where the 95\%-confidence intervals for each main effect smoothing spline do not overlap indicate the regions where the two curves are significantly different.

\section{The experiment \\ Participants}

The experiment involved two sets of participants in order to address two specific questions. First, to determine whether English diphthongs (e.g. /aI/) and French tautosyllabic VG sequences (e.g. /aj/) differ at the phonetic level, 6 adult subjects participated in this experiment: 3 native speakers of English and 3 native speakers of French. The English native speakers were recorded in the US, while the French native speakers were recorded in France.

A second set of participants comprised of bilingual children was also recruited to investigate whether these children maintain separate categories for the diphthongs or whether they equate them. Four French-English bilingual children between the ages of 6 and 7 years old living in the US participated in the experiment (BH, ZM, IP, ZC). Both IP and ZC attend a bilingual school where French and English are used as languages of instruction. $\mathrm{BH}$ and $\mathrm{ZM}$, on the other hand, attend English-only schools. None had any history of speech delay, developmental disability, or neurological impairment.

\section{Stimuli and procedures}

The current study is part of a larger project, which involves four English diphthongs (/aI, av, eI, ov/) and three French VG tautosyllabic sequences (/aj, $\varepsilon j, \mathrm{uj} /$ ) in varying phonetic environments. Using a picture-naming task, multiple repetitions of the stimuli were elicited from each adult monolingual participant in his or her native language and from each bilingual child in both languages. Due to space limitation, this paper only examines a subset of the acquired data, including the English /ai/ (e.g. bye) and /ei/ (e.g. obey) diphthongs in comparison to the French VG sequences /aj/ (e.g. baille 'yawn') and / $/ \varepsilon \mathrm{j} /$ (e.g. abeille 'bee') respectively, following the voiced bilabial stop $/ \mathrm{b} /$. Five repetitions of each word from each participant were 
analyzed for the study. A total number of 140 tokens (20 per bilingual child and 10 per adult monolingual) were included in the analysis. Fifty-point formant contours (F1 and F2) were obtained from each token and submitted to statistical analyses using SSANOVA for the cross-linguistic comparisons of the word-pairs baille vs. bye and abeille vs. obey.

\section{Results}

$Z C$
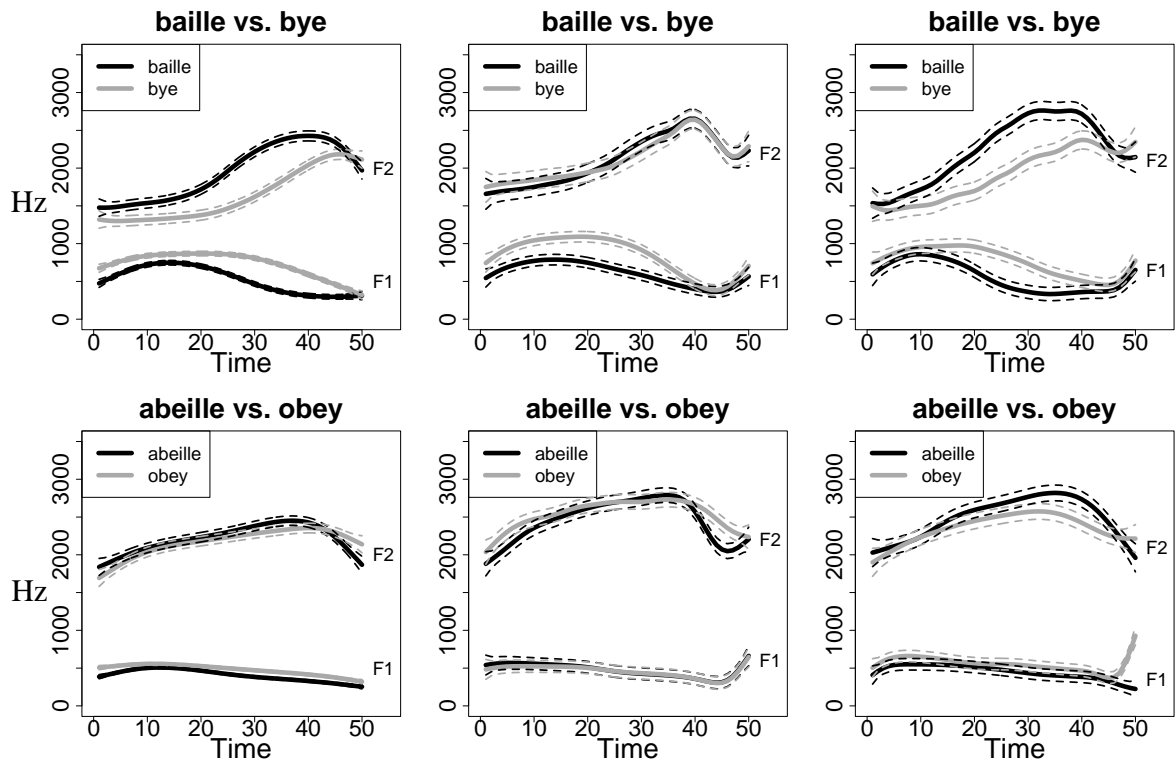

Figure 1. Main effect smoothing spline estimates (solid lines) for crosslinguistic word-pairs with their respective 95\%-confidence intervals (dotted lines) for both F1 and F2.

As illustrated in Figure 1, the adult monolinguals' acoustic implementations of the French and English categories are significantly different for the pair/aj/-/aI/ but not/cj/-/er/, as indicated by the overlapping confidence intervals for the abeille vs. obey comparison. One major difference between baille and bye for the adult groups is the presence of an off-glide on F2 trajectories for the French /aj/ after reaching its target. This off-glide does not occur on the English F2 pattern, which may be an indication that the French category involves an independent glide.

Only two bilingual children are represented in Figure 1, because ZM and IP showed similar patterns as $\mathrm{BH}$ and $\mathrm{ZC}$ respectively. $\mathrm{BH}$ shows overlapping phonetic properties for both /aj/-/ai/ and / $\mathrm{kj} / / \mathrm{eI} /$ pairs. On the other hand, ZC patterns the same way as the adult monolinguals with distinct 
phonetic implementations for /aj/ and /ai/. As for the / $\mathrm{jj} /$-/ei/pair, ZC only shows a slight difference between the two categories, in which the target position of / $\mathrm{jj} /$ appeared to be more front than that of /ei/.

\section{Conclusions}

This study indicated that French-English bilingual children differ in diphthong production as a function of amount of input in each language. While the children who attend bilingual schools managed to maintain separate categories for the English diphthong /ai/ and French VG sequence /aj/, the ones who attend English-only schools produced these categories with overlapping acoustic properties. Although no differences were found for the adults, the slight differences between / $\mathrm{\varepsilon j} /$ and /eI/ for speaker ZC may be attributable to hypercorrection aimed at maximally separating her two languages.

\section{Acknowledgements}

I would like to thank the following people for their input on this work: Lisa Davidson, Maria Grigos, Jon Brennan, and Sean Martin.

\section{References}

Boersma, P., Weenink, D. 2011. Praat: doing phonetics by computer [Computer program]. Version 5.2.22, retrieved 14 April 2011 from http://www.praat.org/

Davidson, L. 2006. Comparing tongue shapes from ultrasound imaging using smoothing spline analysis of variance. Journal of the Acoustical Society of America 120, 407-415.

Flege, J. 2002. Interactions between the native and second language phonetic systems. In Burmeister, P., Piske, T. and Rohde, A. (eds.) 2002. An Integrated View of Language Development: Papers in Honor of Henning Wode, 217-244. Wissenschafftlicher Verlag Trier: Trier.

Harrington, J., Cassidy, S. 1994. Dynamic and target theories of vowel classification: evidence from monophthongs and diphthongs in Australian English. Language and Speech 37, 357-373.

Tsukada, K. 2008. An acoustic comparison of English monophthongs and diphthongs produced by Australian and Thai speakers. English World-Wide 29, 194-211.

Tsukada, K., Birdsong, D., Bialystok, E., Mack, M., Sung, H., Flege, J. 2005. A developmental study of English vowel production and perception by native Korean adults and children. Journal of Phonetics 33, 263-290. 